\title{
Maternal help-seeking for child developmental concerns: associations with sociodemographic factors
}

Original Article

Valsamma Eapen ${ }^{\mathrm{a}, \mathrm{b}, \mathrm{c}}$, Amelia Walter ${ }^{\mathrm{a}, \mathrm{b}}$, Jane Guan ${ }^{\mathrm{a}}$, Joseph Descallar ${ }^{\mathrm{c}}$, Emma Axelsson ${ }^{\mathrm{b}, \mathrm{d}}$, Stewart Einfeld, John Eastwood ${ }^{\mathrm{c}, \mathrm{f}}$, Elisabeth Murphy ${ }^{\mathrm{g}, \mathrm{h}}$, Deborah Beasley ${ }^{\mathrm{g}}$, Natalie Silove ${ }^{\mathrm{i}}$, Cheryl Dissanayake, Sue Woolfenden ${ }^{\mathrm{k}}$, Katrina Williams ${ }^{\mathrm{l}, \mathrm{m}}$, Bin Jalaludin', and the 'Watch Me Grow'study group*

*The 'Watch Me Grow' study group comprises of Cherie Butler, Janelle Cleary, Rudi rn ec, April Deering, Pankaj Garg, Mary Ha, Alexandra Hendry, Trinh Ha, Susan Harvey, Feroza Khan, Nicole Lees, Stephen Matthey, Laura Nicholls, Van Nguyen, Bronwyn Overs, Tara Shine, Kate Short, Olivia Wong and Banosha Yakob.

${ }^{\mathrm{a}}$ School of Psychiatry

University of New South Wales

Sydney NSW 2052

${ }^{\mathrm{b}}$ Academic Unit of Child Psychiatry South West Sydney (AUCS)

South Western Sydney Local Health District

Liverpool Hospital

Elizabeth Street

Liverpool NSW 2170

${ }^{\mathrm{c}}$ Ingham Institute for Applied Medical Research

South Western Sydney Local Health District

1 Campbell Street

Liverpool NSW 2170

${ }^{\mathrm{d}}$ Research School of Psychology

Australian National University

Science Road

Canberra ACT 2601

${ }^{\mathrm{e}}$ Centre for Disability Research and Policy

University of Sydney

Camperdown NSW 2006

f School of Women's and Children's Health

University of New South Wales

This is the author manuscript accepted for publication and has undergone full peer review but has not been through the copyediting, typesetting, pagination and proofreading process, which may lead to differences between this version and the Version of Record. Please cite this article as doi: $10.1111 /$ jpc.13607

This article is protected by copyright. All rights reserved. 
Sydney NSW 2052

${ }^{\mathrm{g}}$ Office of Kids and Families

NSW Ministry of Health, Child and Family Health

73 Miller Street

North Sydney NSW 2060

${ }^{\mathrm{h}}$ Child Health, School of Medicine

University of Notre Dame

Broadway NSW 2007

${ }^{\mathrm{i}}$ Child Development Unit

The Children's Hospital at Westmead

212 Hawkesbury Road

Westmead NSW 2145

${ }^{\mathrm{j}}$ School of Psychology and Public Health

La Trobe University

Bundoora VIC 3086

${ }^{\mathrm{k}}$ Community Child Health

Sydney Children's Hospital Randwick

High Street

Randwick NSW 2031

${ }^{1}$ Department of Paediatrics

University of Melbourne

Parkville VIC 3052

${ }^{\mathrm{m}}$ Developmental Medicine

The Royal Children's Hospital

50 Flemington Road

Parkville NSW 3052

\section{Corresponding author:}

Professor Valsamma Eapen

Professor and Chair, Infant, Child and Adolescent Psychiatry

Academic Unit of Child Psychiatry South West Sydney (AUCS)

South Western Sydney Local Health District

Liverpool Hospital

ICAMHS, Mental Health Centre (Level L1)

Locked Bag 7103

Liverpool BC NSW 1871

Australia 
Tel: +61 296164205

Fax: +61 296012773

Email: v.eapen@unsw.edu.au

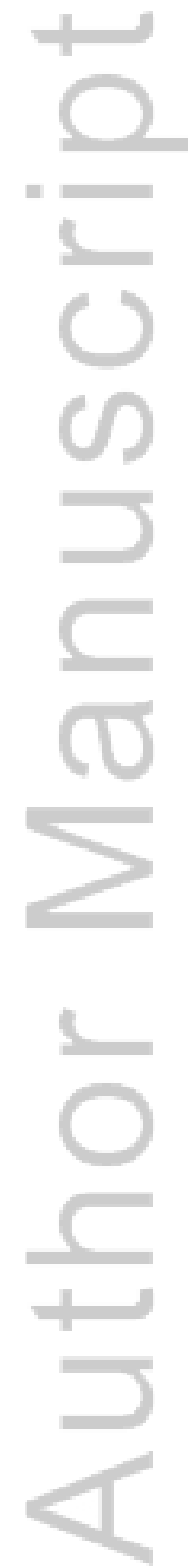

This article is protected by copyright. All rights reserved. 
Maternal help-seeking for child developmental concerns: associations with sociodemographic factors

\section{Abstract}

Aim: To examine sociodemographic factors associated with maternal help-seeking for child developmental concerns in a longitudinal birth cohort study. An understanding of these factors is critical to improving uptake of services to maximise early identification and intervention for developmental concerns. Methods: A birth cohort was recruited from the postnatal wards of two teaching hospitals and through community nurses in South Western Sydney, Australia, between November 2011 and April 2013. Of the 4047 mothers approached, 2025 consented to participate (response rate $=50 \%$ ). Sociodemographic and service use information was collected after the child's birth and when the child was 18 months of age. Sources of help were divided into three categories (formal health services, other formal services, informal supports) and compound variables were created by summing the number of different sources identified by mothers. Results: Significantly more sources of help were intended to be used and/or actually accessed by mothers born in Australia, whose primary language was English, with higher levels of education and annual household income, and among mothers of first-born children. Conclusions: Developmental concerns are known to increase with increased psychosocial adversity. Our findings of reduced intent to access and use of services by socioeconomically disadvantaged families and those from culturally and linguistically diverse backgrounds suggests that an inverse care effect is in operation whereby those children with the greatest health needs may have the least access to services. Possible explanations for this, and recommendations for improving service accessibility for these populations through targeted and culturally-appropriate services, are discussed.

Key words: help-seeking behaviour; developmental disabilities; child development; developmental surveillance; early diagnosis; early intervention 


\section{What is already known on this topic:}

- Early intervention is beneficial for children with developmental disorders but early detection remains a challenge.

- Children from disadvantaged backgrounds, who often have higher developmental risk, also have less access to surveillance and healthcare.

\section{What this paper adds:}

- In a large birth cohort from South Western Sydney, there is reduced intent to access and use of services among socioeconomically disadvantaged families and those of culturally and linguistically diverse backgrounds.

- Policy development and service delivery efforts should include a framework of proportionate universalism to ensure equitable access to and uptake of child health services for all parents.

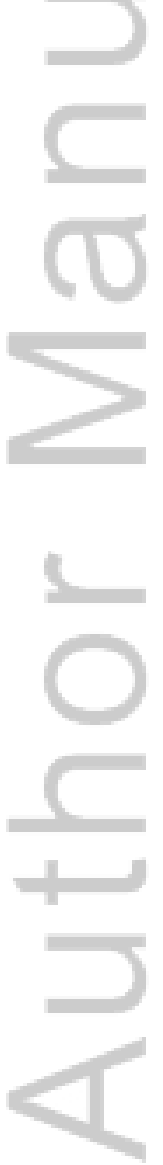

This article is protected by copyright. All rights reserved. 


\section{Introduction}

Developmental disorders are a major cause of global disease burden ${ }^{1,2}$. Early detection and intervention for developmental disorders remains a challenge, despite research showing superior outcomes for children accessing intervention at the earliest possible age $\mathrm{e}^{3,4}$. In Australia, nearly one quarter of children start primary school with developmental vulnerabilities, but most have had no intervention ${ }^{5}$. Identifying at-risk children is particularly challenging, with research suggesting an inverse care effect such that children from disadvantaged backgrounds, who have a heightened risk for developmental disorders, also have lower attendance at surveillance programs and less access to preventative and comprehensive healthcare ${ }^{6,7}$.

Research suggests that families experiencing disadvantage tend to seek less help for developmental concerns than other families. Parents of low socioeconomic status (SES) are less likely to attend universally-offered parenting classes ${ }^{8}$, to seek help for concerns about their child's communication ${ }^{9}$, and to access allied health services for their child's developmental and behavioural disorders ${ }^{10-12}$ than those of higher SES, although these associations may be attenuated in countries with universal healthcare systems such as Australia ${ }^{13}$. Parents' ethnicity and language may also influence helpseeking for developmental concerns. In the United States, African-American parents expressed more negative expectations about treatment than Caucasian parents when seeking professional help for their children with behavioural issues ${ }^{14}$. In Australia, infants from indigenous and culturally and linguistically diverse (CALD) backgrounds have higher parent-reported unmet needs than infants from non-indigenous and English-speaking backgrounds ${ }^{15}$.

It is important to understand factors that are associated with the likelihood of parents seeking help for concerns regarding their child's development in order to improve uptake of available services and ensure that all children receive timely diagnosis and intervention for developmental concerns. An awareness of factors that may be associated with reduced service uptake is necessary in order to identify population groups that may be at risk of not accessing services and to inform research into targeted engagement efforts for these groups, such as trials comparing different methods of engaging at-risk populations. The aim of the current study was to examine sociodemographic factors associated with maternal help-seeking patterns - both intended and accessed sources of support - for concerns about their child's development during the first 18 months of their child's life. 


\section{Materials and Methods}

\section{Ethical approval}

The study was approved by the Human Research Ethics Committees of the University of New South Wales and South Western Sydney Local Health District, and conformed to the standards of the Declaration of Helsinki. All families recruited to the study provided informed consent to participate.

\section{Participants}

A longitudinal birth cohort was recruited from the postnatal wards of two teaching hospitals and through community nurses in South Western Sydney, Australia, between November 2011 and April 2013 for the 'Watch Me Grow' (WMG) study. The WMG study was designed to evaluate the feasibility of current developmental surveillance systems in NSW and their accuracy in identifying children with or at risk of developmental disorders. Of the 4047 mothers approached, 2025 (50\%) consented to participate. Further information on recruitment and methodology is presented elsewhere by Eapen, Woolfenden, Williams et al. ${ }^{16}$.

\section{Measures}

Sociodemographic and service use information was collected via surveys administered to mothers at two time points - shortly after birth (baseline survey) and when children were 18 months of age (18-month survey). Surveys were designed to assess variables known to be important for child health and development based on existing literature and questionnaires from other Australian cohort studies $^{17,18}$. Baseline survey data was available for $1763(87 \%)$ participants while 18-month survey data was available for 482 (24\%) participants.

Mothers were asked two questions to assess help-seeking intentions and actual service use: "Where would you get information about your child's development if you needed it?" (baseline survey), and "Since your child was born, where have you tried to get information about your child's development, if you needed it?" (18-month survey). Mothers were asked to select as many options as applied from a list (see Table 1) and to identify any additional services that were not on the list. Fathers' responses to these questions were not collected, partly because they were usually not present when questionnaires were completed, with most baseline surveys administered on the postnatal wards. Further, due to the primary caregiving role generally being assumed by mothers (over 99\% of mothers in the present sample identified themselves as the child's primary caregiver), our study aimed to examine factors associated specifically with maternal help-seeking. 
\{Insert Table 1 here\}

\section{Statistical analysis}

Sources of help were categorised into: 1. formal health services, 2. other formal services, and 3. informal supports (see Table 1). Literature on help-seeking typically distinguishes between two sources of help - informal and formal. Given that timely detection of and intervention for developmental concerns is best achieved through direct engagement with health services, it was considered important in the present study to further divide formal services into two categories health services and other (non-health) services. Compound variables were created by summing the number of sources of help (total, formal health, other formal, informal) that mothers intended to use (baseline survey) and those that they had accessed in the 18 months following their child's birth (18-month survey), resulting in eight dependent variables. Sociodemographic variables were maternal marital status, country of birth, education and primary language, post-tax annual household income, and the child's birth order (see Table 2).

\section{\{Insert Table 2 here $\}$}

To account for possible overdispersion of each of the dependent variables, likelihood ratio tests were run to determine which of Poisson or negative binomial regression models were more appropriate for analyses in the univariate models. Starting with variables with $p<0.2$ in univariate models, multivariable Poisson or negative binomial regression models were used to determine predictors of each outcome. Variables were removed in a backward stepwise method. A p-value $<$ 0.05 was considered statistically significant.

\section{Results}

\section{Commonly identified help sources}

The mean number of help sources identified by mothers at both baseline (those that they intended to use) and 18-month surveys (those that they actually accessed) is shown in Table 3.

\{Insert Table 3 here $\}$

Formal health services were identified as intended sources of support and accessed more frequently than informal supports and other formal services. There was limited awareness or use of other 
formal services in the current sample, with $62.7 \%$ of mothers not intending to use and $81.3 \%$ of mothers not having accessed these services at baseline and 18-month surveys respectively. GPs were the most frequently identified intended source of help at the child's birth (68.8\% of mothers) and the most accessed help source at 18 months (64.1\% of mothers). Other common intended and accessed sources of help included family and friends $(59.2 \%$ and $42.3 \%$ of mothers at birth and 18 months of age respectively), the internet and books (50.8\% and 57.1\% of mothers), and CFHNs (31.6\% and $25.3 \%$ of mothers).

Fisher's exact tests were run in order to examine whether there was an increased likelihood of mothers accessing a GP or CFHN by the 18-month survey - services that form part of routine developmental surveillance in NSW - if they had reported intention to use these at their child's birth. Thirty-six percent of mothers who had identified CFHNs as an intended source of help at their child's birth had accessed a CFHN by the 18-month survey, compared to only $18 \%$ of mothers who had not identified this at birth $(\mathrm{p}<0.001)$. There was no significant difference, however, in the proportion of mothers who had attended a GP by the 18-month survey between those who had identified this as an intended source of support at their child's birth and those who had not.

\section{Factors associated with help-seeking intentions and behaviours}

\section{Intended help sources identified at baseline}

Significant associations were found between sociodemographic characteristics (mother's country of birth, primary language and education, annual household income, and the child's birth order) and the number of intended help sources identified by mothers following their child's birth (Table 4).

Mothers who were born in Australia identified on average 23\% more total help sources $(\mathrm{p}<0.001)$, $22 \%$ more formal health services $(\mathrm{p}<0.001)$ and $24 \%$ more informal supports $(\mathrm{p}<0.001)$ than mothers born overseas. Mothers whose primary language was English reported 13\% more total help sources $(p<0.001), 11 \%$ more formal health services $(p=0.04)$ and $64 \%$ more other formal services $(\mathrm{p}<0.001)$ than mothers with a different primary language. Mothers of first-born children reported $7 \%$ more total help sources $(p=0.02)$ and $22 \%$ more other formal services $(p=0.01)$ than mothers whose child was not their first. Further, there was an increase in the number of total help sources $(p<0.001)$ and informal supports $(p<0.001)$ identified by mothers as annual household income increased. 
Mothers with TAFE/undergraduate university education identified 29\% more total help sources than mothers with nil/primary education $(\mathrm{p}=0.02), 16 \%$ more total help sources than mothers with Year 10 or 12 education $(\mathrm{p}<0.001)$, and $12 \%$ more total help sources than mothers with postgraduate university education $(\mathrm{p}=0.02)$. Mothers with TAFE/undergraduate university education also reported $20 \%$ more formal health services than postgraduate university graduates ( $\mathrm{p}$ $=0.01)$ and $15 \%$ more formal health services than Year 10 or 12 graduates $(p<0.001)$. Mothers with tertiary qualifications (TAFE/undergraduate university or postgraduate university respectively) identified more informal supports than mothers without tertiary qualifications: $23 \%(\mathrm{p}<0.001)$ and $29 \%(p=0.002)$ more than mothers with Year 10 or 12 education, and $77 \%(p=0.008)$ and $86 \%(p$ $=0.005)$ more than those with primary school or less.

\section{Help sources accessed by 18-month survey}

Final multivariable Poisson regression models are shown in Table 5. The number of help sources accessed during the first 18 months of the child's life was significantly associated with maternal primary language and the child's birth order.

Mothers whose primary language was English reported accessing 21\% more total help sources $(p=$ $0.004), 169 \%$ more other formal services $(p<0.001)$ and $26 \%$ more informal supports $(p=0.02)$ than mothers with a different primary language. Mothers of first-born children accessed $35 \%$ more total help sources $(p<.0001), 22 \%$ more formal health services $(p=0.02), 98 \%$ more other formal services $(p=0.001)$ and $37 \%$ more informal supports $(p=0.002)$ than mothers whose child was not their first.

\{Insert Tables 4 and 5 here $\}$

\section{Discussion}

The aim of this study was to examine sociodemographic factors associated with maternal helpseeking for child developmental concerns during the first 18 months of life. Results showed that mothers born in Australia and whose primary language was English intended to use more help sources following their child's birth than mothers born overseas or who spoke a different primary language. Mothers whose primary language was English also accessed help from more sources during the first 18 months of their child's life than mothers with another primary language. While language is likely to be a barrier to access, previous research has shown that infants from CALD backgrounds are less likely to receive services even if their mothers speak English proficiently ${ }^{19}$, 
suggesting that differences in knowledge, cultural attitudes and/or beliefs about the role of healthcare services may also be contributing factors.

Birth order was associated with help-seeking intentions in the present study, with mothers of firstborn children identifying and accessing more sources of help than mothers with later born children. There are several plausible explanations for this, including increased efforts by services to engage new mothers, higher anxiety about child development in first-time mothers resulting in increased service use, and practical difficulties in attending services when there are multiple children in the family.

Differences also emerged in the number of identified help sources between mothers from different educational and socio-economic backgrounds. Mothers with tertiary qualifications and higher annual household incomes intended to use more sources of help at their child's birth than those with primary or secondary qualifications and lower annual household incomes. This is partially consistent with findings from previous studies that parents from low SES backgrounds are less likely to seek help for their child's developmental disorders ${ }^{10-12}$. However, there were no significant differences in the number of help sources accessed by mothers in the first 18 months of their child's development based on their education or income level. Previous research into the impact of maternal education on help-seeking behaviour has been inconsistent, with some studies finding increased service use among mothers with higher education levels ${ }^{19}$ and others suggesting the opposite pattern $^{20}$. One explanation for this discrepancy is that higher levels of education could plausibly be associated with increased service use due to awareness of available services and greater capacity to afford these, or with decreased service use due to time constraints as a result of differences in type of employment and working hours. It is important that future studies control for potential confounding variables, including SES and employment status, in order to clarify the relationship between education and help-seeking behaviour. Studies using qualitative approaches may also assist in disentangling motivations for different help-seeking patterns.

Previous research suggests that children from low SES and CALD backgrounds are more likely to be developmentally vulnerable and thus most in need of universal developmental surveillance and related services ${ }^{5,7}$. Thus, the present study is strengthened by the recruitment of a birth cohort from a culturally and linguistically diverse area of Sydney, increasing sample representativeness. As with many other studies, mothers were the focus because of their availability and identified role as primary caregiver. Fathers will, however, influence help-seeking behaviour for child development concerns, and exploration of their help-seeking and how that interacts with mothers' help-seeking 
could further assist service development. Our findings of reduced intent to access and use of services among socioeconomically disadvantaged families and those from CALD backgrounds support an inverse care effect where children with the greatest health needs have the least access to services $^{6}$. Compounding this further, additional analysis showed that mothers from disadvantaged backgrounds - those who were born overseas and those with lower annual household incomes were more likely to drop out of the study prior to and were therefore under-represented at the 18month survey. Thus, in addition to the inverse care effect - mothers and children from disadvantaged backgrounds having reduced access to services, our findings suggest that these mothers and children may also be under-represented in research which aims to remediate this very effect.

It is important to acknowledge the complex influences that may impact on service uptake. For example, even if parents are aware of services, a lack of understanding of their value or benefit or beliefs about developmental concerns' lack of response to treatment, could contribute to reduced help-seeking. Further, the cultural appropriateness of services is likely to influence families' willingness to seek support, and the question of how services can better engage and meet the needs of disadvantaged and culturally diverse families is important. Further, parents may vary in their knowledge of age-appropriate development and this can result in either service overuse or underutilisation. Increasing health literacy so that parents can identify whether their child is developing typically and are aware of available support services is important to ensure equitable access to health services. Initiatives such as the Raising Children website ${ }^{21}$, providing evidencebased information and resources for parents, are important in this regard. As such, one limitation of the present study is that mothers were asked to identify where they had sought help for child developmental concerns if they had needed it. It is therefore not possible to determine whether reduced service uptake was because mothers did not have concerns about their child's development (appropriate lack of help-seeking) or due to a lack of awareness or reluctance to access services even in the presence of concerns. Our findings of reduced service use among populations known to be at greater developmental risk, however, suggests that this result is unlikely to be solely attributable to a lack of developmental concern. Further, while it was not a focus of the present study, a previous publication from the WMG study examined the prevalence of parental concerns regarding development at 18 months within the same cohort. Of the 565 children for whom the Parents' Evaluation of Developmental Status (PEDS) ${ }^{22}$ had been completed at 18 months, 184 $(32.6 \%)$ were identified as at high or moderate developmental risk ${ }^{23}$. 
The drop in response rate from $87 \%$ of participating mothers at baseline to $24 \%$ at the 18 -month follow-up is a further limitation of the present study. While a small number of participants chose to withdraw from the study (4\% of the overall sample of 2025), the drop is response rate is largely due to the research team being unable to contact participants at the 18-month follow-up. Several efforts were made to try to overcome this, including multiple methods of contact and multiple attempts at follow-up phone calls - at least three attempts were made to contact each participant - but the reduced response rate, particularly among more disadvantaged families, does highlight the additional efforts that may be needed to engage certain families in services. More effective methods of follow-up than phone calls are required to address the significant challenge of cohort retention. Adequate resources for a study director and ongoing participant engagement strategies, such as collaborative research planning, home visiting, study information days and community presentations, have been suggested as strategies that have been used with success in other Australian cohort studies ${ }^{23}$.

Despite these limitations, the findings of the present study support the use of a framework of proportionate universalism, in which services are available to all children but the level of support is commensurate with the unique needs of individual children and their families ${ }^{24}$, such that targeted and culturally-appropriate services are provided to meet the additional needs of those at increased biological or psychosocial risk. While such a framework is an integral part of current NSW Health policy, there are significant challenges in the resourcing of services to implement the policy given the finite health budget and competing priorities. However, since early identification of developmental concerns is the essential first step in ensuring that children receive timely intervention, no effort should be spared in promoting help-seeking by parents.

This article is protected by copyright. All rights reserved. 


\section{Acknowledgements}

This study (APP1013690) was funded by the NH\&MRC in Australia, through a partnership grant with the New South Wales Department of Health, Kids and Families, and in-kind support from the University of New South Wales, La Trobe University, South Western Sydney Local Health District and Sydney Children's Hospital Network.

We thank Professor Margot Prior for her contribution to the development of the research proposal, the Child and Family Health Nurses in the Liverpool/Fairfield/Bankstown areas and their managers Trish Clarke, Victoria Blight and Wendy Geddes, the staff of the postnatal wards at Liverpool and Bankstown Hospitals, the staff at the Clinical Information Department at Liverpool Hospital, as well as research staff.

The 'Watch Me Grow' study group comprises of Cherie Butler, Janelle Cleary, Rudi rn ec, April Deering, Pankaj Garg, Mary Ha, Alexandra Hendry, Trinh Ha, Susan Harvey, Feroza Khan, Nicole Lees, Stephen Matthey, Laura Nicholls, Van Nguyen, Bronwyn Overs, Tara Shine, Kate Short, Olivia Wong and Banosha Yakob.

This article is protected by copyright. All rights reserved. 


\section{References}

1. Scherzer AL, Chhagan M, Kauchali S, et al. Global perspective on early diagnosis and intervention for children with developmental delays and disabilities. Developmental Medicine \& Child Neurology. 2012;54(12):1079-84.

2. Lancet Early Childhood Development Series. Advancing Early Childhood Development: from Science to Scale. The Lancet. 2017;389.

3. Wallace KS, Rogers S. Intervening in infancy: implications for autism spectrum disorders. J Child Psychol Psychiatry. 2010;51(12):1300-20. PubMed PMID: 20868374. Epub 2010/09/28.

4. Eapen V, rn ec R, Walter A. There are gains, but can we tell for whom and why? Predictors of treatment response following group Early Start Denver Model intervention in preschool-aged children with Autism Spectrum Disorder. Autism - Open Access. 2016;6(1):168-78.

5. Goldfeld S, O'connor M, Sayers M, et al. Prevalence and correlates of special health care needs in a population cohort of Australian children at school entry. Journal of Developmental \& Behavioral Pediatrics. 2012;33(4):319-27.

6. Hart JT. The inverse care law. The Lancet. 1971;297(7696):405-12.

7. Woolfenden S, Eapen V, Williams K, et al. A systematic review of the prevalence of parental concerns measured by the Parents' Evaluation of Developmental Status (PEDS) indicating developmental risk. BMC pediatrics. 2014;14(1):231.

8. Reedtz C, Martinussen M, Wang Jørgensen F, et al. Parents seeking help in child rearing: who are they and how do their children behave? Journal of Children's Services. 2011;6(4):264-74.

9. Skeat J, Eadie P, Ukoumunne O, et al. Predictors of parents seeking help or advice about children's communication development in the early years. Child: care, health and development. 2010;36(6):878-87.

10. Thomas KC, Ellis AR, McLaurin C, et al. Access to care for autism-related services. Journal of Autism and Developmental Disorders. 2007;37(10):1902-12.

11. McCallum SM, Rowe HJ, Gurrin L, et al. Unsettled infant behaviour and health service use: A cross-sectional community survey in Melbourne, Australia. Journal of Paediatrics and Child Health. 2011;47(11):818-23.

12. Pavuluri MN, Luk S-L, McGee R. Help-seeking for behavior problems by parents of preschool children: A community study. Journal of the American Academy of Child \& Adolescent Psychiatry. 1996;35(2):215-22.

13. Zwaanswijk M, Verhaak PF, Bensing JM, et al. Help seeking for emotional and behavioural problems in children and adolescents. European Child \& Adolescent Psychiatry. 2003;12(4):15361.

14. Bussing R, Zima BT, Gary FA, et al. Barriers to detection, help-seeking, and service use for children with ADHD symptoms. The Journal of Behavioral Health Services \& Research. 2003;30(2):176-89.

15. Ou L, Chen J, Garrett P, et al. Ethnic and Indigenous access to early childhood healthcare services in Australia: parents' perceived unmet needs and related barriers. Australian and New Zealand Journal of Public Health. 2011;35(1):30-7.

16. Eapen V, Woolfenden S, Williams K, et al. Are you available for the next 18 months? Methods and aims of a longitudinal birth cohort study investigating a universal developmental surveillance program: the 'Watch Me Grow' study. BMC pediatrics. 2014;14(1):234-42.

17. Nicholson JM, Sanson A. A new longitudinal study of the health and wellbeing of Australian children: how will it help? Medical Journal of Australia. 2003;178(6):282-4.

18. Comino E, Craig P, Harris E, et al. The Gudaga Study: establishing an Aboriginal birth cohort in an urban community. Australian and New Zealand Journal of Public Health. 2010;34(s1):S9-S17.

19. Ou L, Chen J, Hillman K. Health services utilisation disparities between English speaking and non-English speaking background Australian infants. BMC Public Health. 2010;10(1):182-94. 
20. Golenko XA, Shibl R, Scuffham PA, et al. Relationship between socioeconomic status and general practitioner visits for children in the first 12 months of life: an Australian study. Australian Health Review. 2015;39(2):136-45.

21. Raising Children Network Australia Limited. 2015 [09/11/2015]. Available from: raisingchildren.net.au.

22. Glascoe FP. Parents' evaluation of developmental status (PEDS). Ellsworth \& Vandermeer Press, Ltd. 1997.

23. Woolfenden S, Eapen V, Jalaludin B, et al. Prevalence and factors associated with parental concerns about development detected by the Parents' Evaluation of Developmental Status (PEDS) at 6-month, 12-month and 18-month well-child checks in a birth cohort. BMJ open. 2016;6(9):e012144.

24. Marmot M. Fair society, healthy lives. Inequalities in health: Concepts, measures, and ethics. 2010:282.

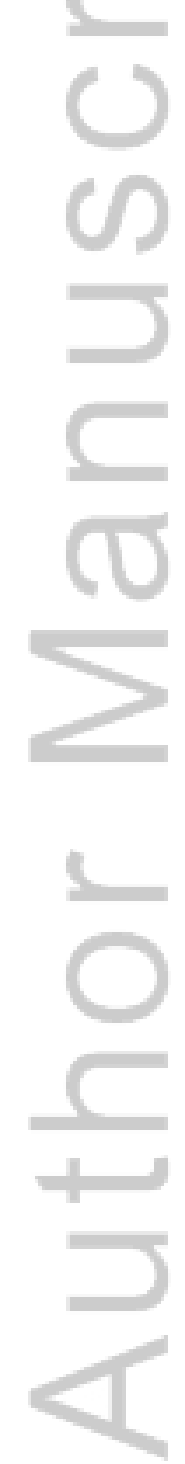

This article is protected by copyright. All rights reserved. 
Table 1: Sources of help included in baseline and 18-month surveys

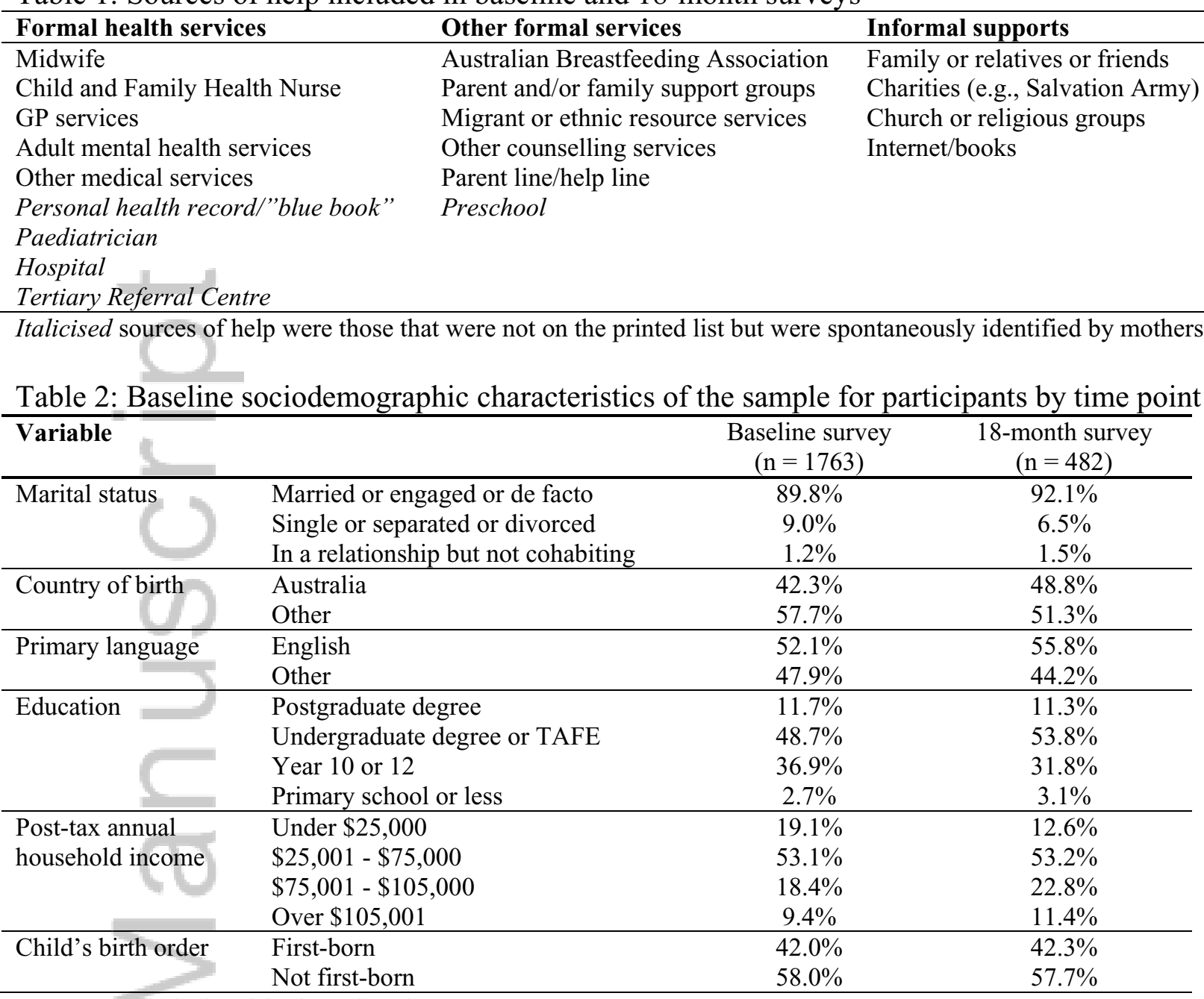

TAFE $=$ Technical and further education

Table 3: Mean number of help sources identified by mothers

\begin{tabular}{lcccc}
\hline Variable & Mean & SD & Range & \% identifying 1 or more \\
\hline Baseline survey (intended), $n=1741$ & 3.3 & & & \\
Total help sources & 2.0 & $0-14$ & $99.4 \%$ \\
Formal health services & 1.6 & 1.0 & $0-5$ & $88.1 \%$ \\
Informal supports & 1.2 & 0.8 & $0-4$ & $75.3 \%$ \\
Other formal services & 0.6 & 0.9 & $0-5$ & $37.3 \%$ \\
\hline 18-month survey (accessed), $n=482$ & & & \\
Total help sources & 2.3 & 1.4 & $0-9$ & $97.3 \%$ \\
Formal health services & 1.1 & 0.8 & $0-4$ & $75.9 \%$ \\
Other formal services & 0.2 & 0.5 & $0-3$ & $18.7 \%$ \\
Informal supports & 1.0 & 0.7 & $0-3$ & $73.0 \%$ \\
\hline
\end{tabular}


Table 4: Final multivariable models of number of intended help sources (baseline survey)

\begin{tabular}{|c|c|c|c|c|c|c|c|c|c|c|c|c|}
\hline \multirow{2}{*}{$(\mathrm{O})$} & \multicolumn{3}{|c|}{ Total help sources ${ }^{\ddagger}$} & \multicolumn{3}{|c|}{ Formal health services ${ }^{\dagger}$} & \multicolumn{3}{|c|}{ Informal supports ${ }^{\dagger}$} & \multicolumn{3}{|c|}{ Other formal health services ${ }^{\ddagger}$} \\
\hline & $\mathrm{RR}$ & $95 \% \mathrm{CI}$ & p-value & $\mathrm{RR}$ & $95 \% \mathrm{CI}$ & p-value & $\mathrm{RR}$ & $95 \% \mathrm{CI}$ & $\mathrm{p}$-value & $\mathrm{RR}$ & $95 \% \mathrm{CI}$ & p-value \\
\hline Mother's Country of Birth & \multirow{3}{*}{1.23} & \multirow{3}{*}{$\begin{array}{l}(1.15,1.32) \\
\text { Reference }\end{array}$} & \multirow{3}{*}{$<0.001$} & \multirow{3}{*}{1.22} & \multirow{3}{*}{$\begin{array}{l}(1.10,1.34) \\
\text { Reference }\end{array}$} & \multirow{3}{*}{$<0.001$} & \multirow{3}{*}{1.24} & \multirow{3}{*}{$\begin{array}{l}(1.12,1.37) \\
\text { Reference }\end{array}$} & \multirow{3}{*}{$<0.001$} & & & \\
\hline Australia & & & & & & & & & & & & \\
\hline Other & & & & & & & & & & & & \\
\hline Mother's Education & & & $<0.001$ & & & 0.005 & & & $<0.001$ & & & \\
\hline Postgrad university & 1.15 & $(0.92,1.45)$ & 0.23 & 1.01 & $(0.74,1.38)$ & 0.95 & 1.86 & $(1.2,2.9)$ & 0.006 & & & \\
\hline TAFE or undergrad university & 1.29 & $(1.04,1.60)$ & 0.02 & 1.21 & $(0.91,1.62)$ & 0.19 & 1.77 & $(1.16,2.72)$ & 0.008 & & & \\
\hline Year 10 or 12 & 1.11 & $(0.9,1.38)$ & 0.34 & 1.06 & $(0.79,1.42)$ & 0.71 & 1.45 & $(0.94,2.22)$ & 0.09 & & & \\
\hline Primary school or less & & Reference & & & Reference & & & Reference & & & & \\
\hline Primary Language & & & & & & & & & & & & \\
\hline English Only & 1.13 & $(1.06,1.22)$ & $<0.001$ & 1.11 & $(1.00,1.22)$ & 0.04 & & & & 1.64 & $(1.40,1.93)$ & $<0.001$ \\
\hline Others Spoken & & Reference & & & Reference & & & & & & Reference & \\
\hline Income (After Tax) & & & $<0.001$ & & & & & & $<0.001$ & & & \\
\hline$<\$ 25,000$ & 0.76 & $(0.68,0.86)$ & $<0.001$ & & & & 0.69 & $(0.56,0.84)$ & $<0.001$ & & & \\
\hline$\$ 25,000-\$ 75,000$ & 0.90 & $(0.82,0.99)$ & 0.03 & & & & 0.90 & $(0.77,1.06)$ & 0.20 & & & \\
\hline$\$ 75,000-\$ 105,000$ & 0.97 & $(0.87,1.07)$ & 0.53 & & & & 1.00 & $(0.84,1.19)$ & 0.98 & & & \\
\hline$>\$ 105,000$ & & Reference & & & & & & Reference & & & & \\
\hline $\begin{array}{l}\text { Birth Order } \\
\text { First-born child }\end{array}$ & 107 & & 0.02 & & & & & & & 122 & & 0.01 \\
\hline $\begin{array}{l}\text { First-born child } \\
\text { Not first-born }\end{array}$ & 1.07 & $\begin{array}{l}\text { (1.01, } 1.13) \\
\text { Reference }\end{array}$ & 0.02 & & & & & & & 1.22 & $\begin{array}{l}\text { (1.05, 1.4L) } \\
\text { Reference }\end{array}$ & 0.01 \\
\hline
\end{tabular}

${ }^{\ddagger}$ Results based on negative binomial regression. ${ }^{\dagger}$ Results based on Poisson regression. TAFE $=$ Technical and further education. RR $=$ Relative Risk. 95\% CI $=95 \%$ Confidence Interval. Formal health services refers to GP, other medical service, midwife, child and family health nurse, blue book, adult mental health service, hospital, tertiary referral centre and paediatrician. Other formal health services refers to Australian Breastfeeding Association, parent help line, parent/family support group, migrant/ethnic services, counselling service and preschool. Informal supports refers to family/friends, charities, church/religious groups and internet/books. Total help sources refers to all help sources described.

Table 5: Final multivariable models of number of accessed help sources (18-month survey)

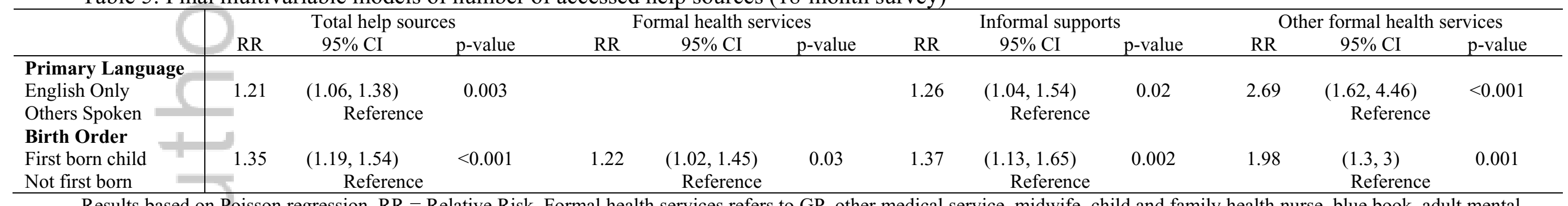

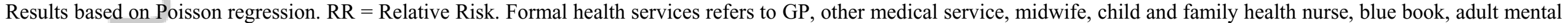

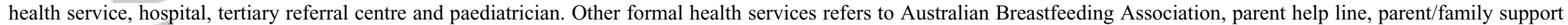

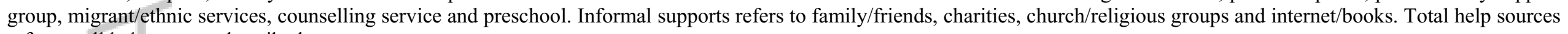
refers to all help sources described.

This article is protected by copyright. All rights reserved. 


\section{University Library}

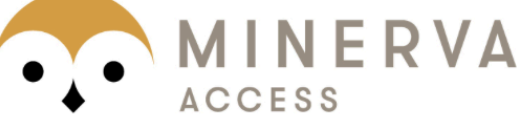

A gateway to Melbourne's research publications

Minerva Access is the Institutional Repository of The University of Melbourne

Author/s:

Eapen, V;Walter, A;Guan, J;Descallar, J;Axelsson, E;Einfeld, S;Eastwood, J;Murphy,

E;Beasley, D;Silove, N;Dissanayake, C;Woolfenden, S;Williams, K;Jalaludin, B

Title:

Maternal help-seeking for child developmental concerns: Associations with sociodemographic factors

Date:

2017-10-01

Citation:

Eapen, V., Walter, A., Guan, J., Descallar, J., Axelsson, E., Einfeld, S., Eastwood, J., Murphy, E., Beasley, D., Silove, N., Dissanayake, C., Woolfenden, S., Williams, K. \& Jalaludin, B. (2017). Maternal help-seeking for child developmental concerns: Associations with socio-demographic factors. JOURNAL OF PAEDIATRICS AND CHILD HEALTH, 53 (10), pp.963-969. https://doi.org/10.1111/jpc.13607.

Persistent Link:

http://hdl.handle.net/11343/293116 